\title{
136-6 UNTANGLING THE ECOLOGY AND FOSSIL PRESERVATION KNOT FOR PALEOZOIC
}

BIOTAS

SALEH, Farid', BATH ENRIGHT, Orla G. ${ }^{2}$, DALEY, Allison C. ${ }^{2}$, PITTET, Bernard", LEFEBVRE, Bertrand and ANTCLIFFE, Jonathan', (1)Laboratoire de Géologie de Lyon: Terre, Planètes, Environnement (UMR 5276, CNRS), Université Claude Bernard Lyon 1, Campus Scientifique de la Doua Bâtiment GEODE, 2, rue Raphaël Dubois, Villeurbanne, 69622, France, (2)Institute of Earth Sciences, University of Lausanne, Lausanne, CH-1015, Switzerland

\section{Abstract}

Fossil deposits are a tangle of multiple signals that make understanding the functioning of past ecosystems a complicated and fraught process. The main difficulty is whether differences between fossil sites show an evolutionary or ecological signal, or are influenced by fossil preservation. These processes are not independent, as anatomical or behavioral differences can alter preservational pathways. It is particularly important to untangle these interacting processes when examining the animal communities of the Cambrian Explosion and Ordovician Radiation, where exceptional preservation of soft tissues provides relatively complete assemblage data. A novel method of data partitioning based on probabilistic modelling is used to examine these factors with respect to The Walcott Quarry, Burgess Shale, Canada (510Ma) and the Fezouata Shale, Morocco (c. 475Ma). As the prototypical Burgess Shale-type locality, the Walcott Quarry, is usually used as a basis for understanding Cambrian community structure and early ecosystem evolution. The result of probabilistic modelling shows that the Walcott Quarry biota best preserves the endobenthic community whilst systematically under-representing the nekton/plankton. The reverse is true for the Fezouata biota, with under-representation of the endobenthos. Taken in concert with data from a bioturbation index for these sites, a new model of comparative taphonomy is developed based on sedimentary input timing with respect to organism mortality. These results suggest that during the Cambrian Explosion and Ordovician Radiation the most exceptional fossils sites must still be calibrated against each other to understand the unfolding evolutionary events and ecosystem structures.

Geological Society of America Abstracts with Programs.

Vol 52, No. 6, 2020

doi: 10.1130/abs/2020AM-348709 